\title{
Aortic Isthmic Rupture by Blast
}

\section{Case Report}

Volume 1 Issue 1- 2021

\begin{abstract}
Author Details
Sobhi Mleyhi ${ }^{1 \star}$, Rim Miri ${ }^{1}$, Imtinen Ben Mrad $^{2}$, Ihsen Zairi², Malek ben Mrad ${ }^{1}$ and Raouf Denguir ${ }^{1}$

${ }^{1}$ University of Tunis el Manar, Faculty of Medicine of Tunis, La Rabta Hospital, Cardiovascular Surgery Department

${ }^{2}$ University of Tunis el Manar, Faculty of Medicine of Tunis, Habib Thameur Hospital, Cardiology Department

*Corresponding author

Dr Sobhi Mleyhi, Cardiovascular surgery departement, La Rabta Hospital Jabbari Street 1007 Tunis, Tunisia

Article History

Received: February 12, 2021 Accepted: April 08, 2021 Published: April 09, 2021
\end{abstract}

\section{Introduction}

The traumatic rupture of the aortic isthmus is a rare event, often fatal, occurring in a context of violent trauma. Blast-related lesions, related to transmission through the body of the shockwave following an explosion, mainly concern the lung parenchyma and the middle ear. Aortic rupture is the main lesion of the large mediastinal vessels and it is exceptionally reported outside of wars.

\section{Clinical Case}

We report the case of a 50-year-old patient with no history of a workrelated accident with a burst of a tire resulting in closed chest trauma with chest pain and dyspnea. Hemodynamic constants were stable. The chest radiograph showed a hemo-pneumothorax on the right which was drained, a hemothorax of average abundance on the left and a fracture involving the anterior arch of the 5th, 8th, 9th and 10th straight sides. The thoracoabdominal CT scan (Figs. 1 and 2) showed a rupture of the aortic isthmus with bilateral pleural effusion of low abundance and hepatic and renal failure foci. The patient was operated on. Under extra-corporal circulation, he/she had an interposition of a Dacron tube No. 24. The operative follow-ups were marked by an agitated awakening. A cerebral CT showed a right hemorrhagic foci, requiring neuroleptics with good evolution.

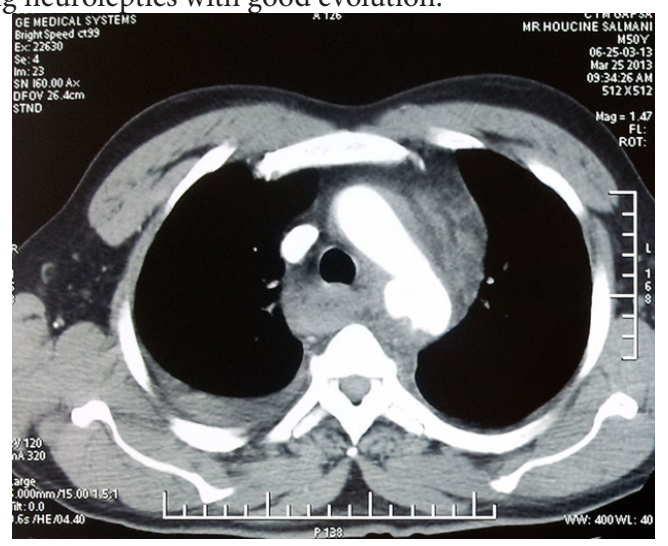

Figure 1: Thoracic CT angiography: transverse section showing the isthmic rupture.

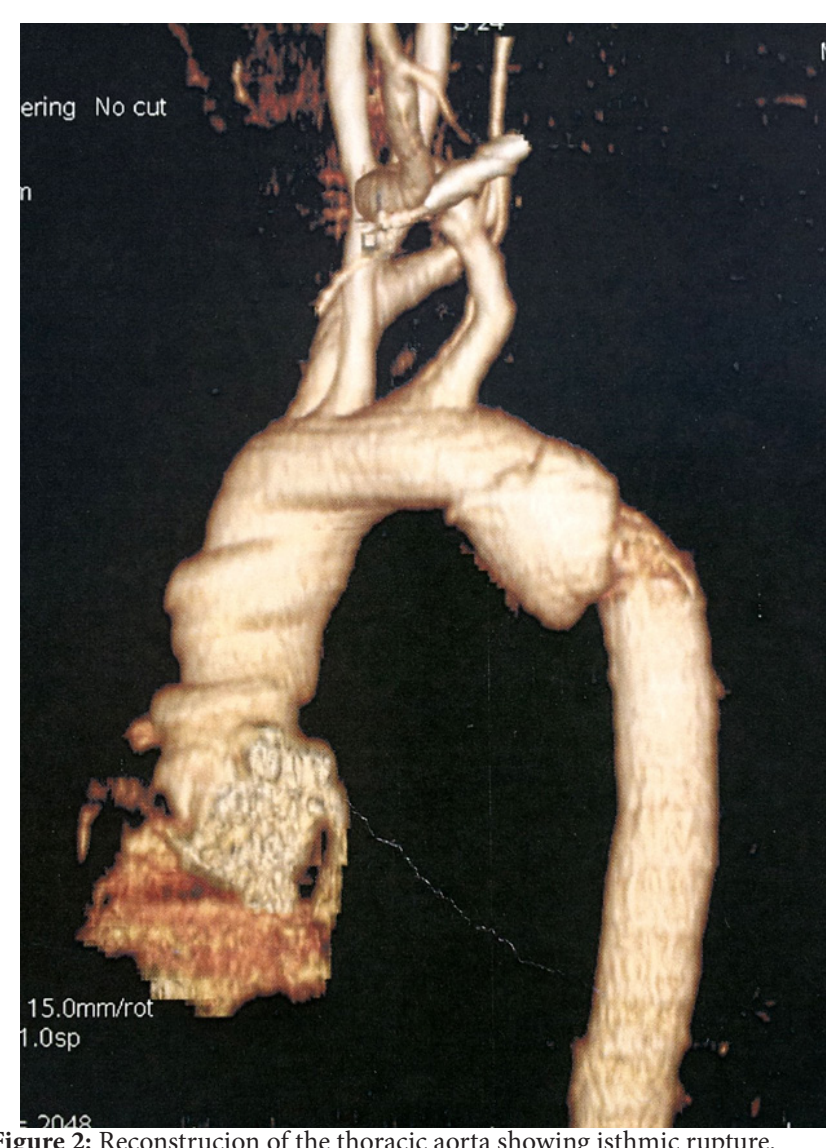

Figure 2: Reconstrucion of the thoracic aorta showing isthmic rupture.

\section{Conclusion}

The primary lesions caused by blast are multiple (pulmonary, tympanic, digestive, cerebral, ocular ...). Among the cardiovascular effects are described hypotension, rhythm disorders, myocardial lesions, but also ruptures of the aortic isthmus which remains rare, whose management must take into account the associated lesions. 